\title{
Accurate Copper Isotope Measurements of a Reference Material NIM- RM2707 by Calibrated Mass Spectrometry
}

\author{
P.S. SONG ${ }^{1}$ AND T. ZHOU ${ }^{2}$
}

${ }^{1}$ National Institute of Metrology, Beijing 100029, China (songpsh@nim.ac.cn)

${ }^{2}$ National Institute of Metrology, Beijing 100029, China (zhoutao@nim.ac.cn)

\section{Objective}

As a transition metal element, copper is widely invovled in planetary differentiation, minerlizaion and biological processes. Accurate $\mathrm{Cu}$ isotopic compositions measurements would provide valuable information to these reasearch areas. Therefore, in this study, we developed a calibrated mass spectrometry method for accurate determination of $\mathrm{Cu}$ isotopic compositions. Meanwhile, a reference material of $\mathrm{Cu}$ isotope ratios NIM-RM2707 was prepared to ensure the traceability and trasmisstion for the measured $\mathrm{Cu}$ isotope values of different labotories and samples.

\section{Results and Discussion}

The calibrated mass spectrometry for the measurement of $\mathrm{Cu}$ isotopic composition was investigated using a Thermo Fisher Scientific Neptune Plus (Bremen, Germany) MCICPMS. Seven synthetic isotope mixures with $\mathrm{Cu}$ isotope ratios close to natural $\mathrm{Cu}$ material were gravimetrically prepared by isotopically enriched $\mathrm{Cu}-63$ and $\mathrm{Cu}-65$. The instrumental mass bias correction factor $K$ was obtained by the MC-ICPMS measurement data of isotopically enriched $\mathrm{Cu}$ solutions and synthetic isotope mixtures using a mathematical iteration method.

For the determination of $\mathrm{Cu}$ isotope ratio, NIM-RM2707 solution was analyzed along with seven synthetic mixtures under the same instrument conditions. As a result, the determined $\mathrm{Cu}$ isotope ratio for NIM-RM2707 was displayed in Table 1, which showed improved uncertainty compared with those of IRMM Cu isotope ratio reference materials AE633 and AE-647.

Table 1: Copper isotope ratios for reference materials NIMRM2707, AE-633 and AE-647

\begin{tabular}{ccc}
\hline \multicolumn{3}{c}{$R_{63 / 65}$} \\
\hline NIM-RM 2707 & AE-633 & AE-647 \\
$2.2442(9)$ & $2.2440(21)$ & $2.2442(37)$ \\
\hline
\end{tabular}

\footnotetext{
${ }^{a}$ The expended standard uncertainties of $k=2$ are given in parentheses.
} 